\title{
The use of interprofessional peer examiners in an objective structured clinical examination: Can dental students act as examiners?
}

\author{
G. R. Ogden, ' M. Green, ${ }^{2}$ and J. S. Ker, ${ }^{3}$
}

Objective To assess whether final year dental students could act as reliable examiners within an Objective Structured Clinical Examination (OSCE) by comparison with results obtained by an experienced member of staff.

Design A station testing examination of the mouth was included in the second year medical undergraduate summative OSCE examination.

Setting Concurrently run in three different examination venues on the Ninewells Hospital campus.

Subjects 147 medical students and 3 pairs (A, B, C) of examiners. Each examining pairing consisted of one member of staff and one dental student (blind to each other's marking).

Method A checklist of 13 tasks to be performed was provided to the examiners. One mark awarded for a completed task, no mark for no attempt at the task, and half a mark for attempt at task.

Results Paired results were available for 125 medical students. Using Mann-Witney analysis, the non-parametric $95 \%$ confidence intervals for the difference in scores between the 3 paired teams were group $A(-0.5,0)$, group $B(-0.5,0.5)$, group $C(-0.5,0)$. In only 4 students (out of 125) did the difference between the individual pair differ by 2 or more marks.

Conclusion On the basis of this pilot study final year dental students may be used as examiners in OSCEs where basic technical skills are to be evaluated. This development from peer group teaching provides further evidence supportive of interprofessional education.

\footnotetext{
There can be few dental surgeons who 1 are not involved in some aspect of educating members of the dental team (eg dental nurses or vocational/general professional trainees). As the role of the dental practitioner evolves, it is important to share educational innovations within the journals they read. Such a strategy has been adopted by the British Medical Journal ${ }^{1}$ and is supported by the creation of an Education Section within the British Dental Journal. This recognises that education and service are complementary to one another.

${ }^{1}$ Professor G. R. Ogden, Section of Oral \& Maxillofacial Surgery; ${ }^{2}$ M. Green, Lecturer, Department of Mathematics, Clinical Skills Unit, ${ }^{3} \mathrm{~J}$.

S. Ker, Lecturer, Ninewells Hospital \& Medical

School, University of Dundee.

Correspondence to: Professor G. R. Ogden, Unit of

Oral Surgery and Medicine, Dundee Dental Hospital

and School, Dundee, DD1 4 HR.

REFEREED PAPER

Received 05.08.99; accepted 05.01.00

(C) British Dental Journal 2000; 189: 160-164
}

To that end examinations should seek to be reliable and valid in assessing performance. ${ }^{2}$ The method of assessment should also encourage lifelong learning strategies through a deep approach to learning. ${ }^{3}$

In the clinical environment the Objective Structured Clinical Examination (OSCE) ${ }^{4}$ is increasingly being used at an undergraduate level to assess competence.

\section{In brief}

This article:

- Illustrates interprofessional education.

- Uses both peer group teaching and assessment.

- Increases awareness by future medical practitioners of the role of the dental surgeon.
Peer teaching has also been shown to be effective in promoting learning in the undergraduate medical curriculum. ${ }^{5}$ In a problem-based course in Brasilia scores of meaningfulness of course experience and group work usefulness were higher in the peer tutored group than in the teacher tutored group. There was no loss of cognitive achievement in the peer tutored group. ${ }^{6}$

The natural progression from the peer teaching and learning process is a move to peer assessment.

In the context of an OSCE the assessment can be dissected to a certain extent to measure the procedural rather than the contextual aspects of a particular skill. When students are novices at the commencement of their clinical programme it is essential to examine discrete aspects of a task. For example, the OSCE can be used to determine a student's performance to demonstrate a procedural skill in the correct sequence. However, in the assessment of performance, it is often difficult to develop an OSCE station that only assesses one aspect of the task. One has to obtain reliability in assessing a task without losing its validity within the context that it is set in. The need to employ an 'expert' examiner may not be necessary. However, to achieve reliability, training in the use of a checklist is required. Arguably less training is required for those with prior knowledge of the subject, since an expert can evaluate the quality of the behaviour and its appropriateness in the given context. ${ }^{7}$ Hence we used dental students in the assessment of oral cavity examination by medical students.

The World Federation for Medical Education Summit in 1993 highlighted the need for feasible educational strategies to equip doctors with the clinical skills to promote health and prevent illness, and to practice in collaboration with other 
healthcare professionals. $^{8}$ Collaboration in healthcare practice requires a knowledge of the scope and unique functions of each contributor to patient care. Collaborative education can prepare students to work collaboratively in later professional life. ${ }^{9}$ When the barriers of professional jargon and ignorance of training programmes are removed there are opportunities for better patient care through shared insight. ${ }^{10}$

Medical curricula have traditionally had little emphasis on oral health issues, ${ }^{11}$ yet in the Health Education Board for Scotland's strategic plan dental and oral health was identified as one of the eight priorities for health education. ${ }^{12}$

Diseases affecting the teeth and mucosa are generally higher in Scotland than in the rest of the UK. ${ }^{13,14}$ Often patients attend their doctor rather than their dentist if they perceive there is something wrong with their mouth. ${ }^{15,16}$ This is often caused by ignorance of the role that GDPs play in the diagnosis and management of oral disease. There is obviously a need to identify areas for collaboration between doctors and dentists in order to offer optimal patient care.

In this paper we report on the performance of final year dental students as assessors of second year medical students using an OSCE.

\section{Method}

Following the publication of Tomorrows Doctors, ${ }^{17}$ the GMC's recommendations on undergraduate medical education in 1993, the University of Dundee developed a spiral integrated three-phase curriculum. ${ }^{18}$ The first two phases are based on the 11 body systems, with the student moving from normal structure function and behaviour in Phase 1 to abnormal structure, function and behaviour in Phase 2 .

There are 12 curriculum outcomes which determine the attributes of a Dundee medical graduate. The students are assessed during each phase of the curriculum on their progress in the 12 outcomes.

The gastroenterology systems teaching in Phase 2 is a 5 -week programme developed by an interprofessional group of healthcare professionals supported by a basic scientist, microbiologist and pathologist.

Oral health is the focal topic of the first week's teaching. Students are given lecture opportunities in relation to caries prevention and an overview of systemic disease affecting the oral cavity, small group activities which relate basic sciences to the topic, and each student participates in a 2hour clinical skills session. At the end of the week students attend the integrated teaching programme which focuses on the integration between healthcare professions, the integration between clinical presentation and pathophysiology, and the integration between primary and secondary care.

The 2-hour clinical skills session uses small group teaching methods and consists of four components:

- Examination of the oral cavity

- Identification of common oral lesions using a video programme

- Taking a history of an oral complaint from a patient

- Examination of patients with oral disease.

The expected outcome from this session is that students would be able to develop their competence in the technical skill of oral examination in the correct sequence and using the appropriate equipment.

Final year dental students were chosen at random from a class of 50 to participate in the teaching programme. The students were undertaking a core teaching attachment in oral surgery.

The clinical programme for medical students is a compulsory programme so all students in second year attended. The students work in groups of eight, randomly allocated at the beginning of Phase 2 .

Eight dental students participated in the programme, two attending each session. The oral surgeon in charge of the programme met with the students prior to the start of the G.I. course. Using the clinical skills tutor manual guidelines given to other medical tutors participating in the programme the students were taught what to cover. The dental students were thus appraised of the course out- comes and their responsibilities in relation to the teaching and learning of oral examination to the second year medical students.

The dental students had to demonstrate examination of the oral cavity to each group of eight to ten medical students. In the demonstration of this, one dental student acted as a 'patient', while the other was the examining 'doctor'. This reenacted the role play that they had been exposed to prior to entering clinics 2.5 years previously. However, it reflected what the dental students were doing practically every day. The 'tools' employed were those readily available in any general medical practice setting (ie disposable gloves, gauze, wooden tongue spatula, light). They then had to oversee the medical students' practise and refine their techniques as required. The medical students were encouraged to take up self revision skills sessions and students were also given the opportunity to refine their skills in oral examination in the integrated teaching programme in the following week. At the end of the 24-week core teaching programme all 144 medical students underwent a 24-station $\mathrm{OSCE}^{4}$ covering all areas taught in the integrated programme'. Errors of rating were minimised by a meeting in which the examiners for all three venues (staff and dental student) were briefed as to their role, the use of the checklist of actions to be performed and the marking system (Fig. 1).

The examination was run over the course of a morning, in three venues within the hospital with two runs of each examination, to ensure all candidates were assessed. The medical students changed stations every 4 to 8 minutes. At one station medical students were given a written scenario in relation to examination of the oral cavity.

The dental student 'examiners' were taken from those that had helped teach the medical students some 3 months earlier.

The checklist (Fig. 1) gave marks for communication skills as well as the sequence of the oral examination.

Two examiners were placed at each site. One a final year dental student and the 
other a member of the dental faculty staff (with at least 5 years postgraduate experience). They were given an identical set of examination papers containing the checklists and medical student matriculation numbers. They were informed that one of their checklists would be used for the final student mark but were not informed which (in the event, only the marks recorded by the member of staff were used). The two examiners were requested not to confer throughout the examination process and the site supervisor in each venue was able to observe the examiners, as the station was near the central organizational point. There were no gaps between medical student assessments and therefore no time for discussions between student and staff examiner.

\section{Results}

The OSCE station relating to examination of the oral cavity had a checklist of 13 points, each with a value of 1 (if correct) or 0 (if incorrect). The examiners were allowed to score 0.5 if the student attempted the examination procedure but did not carry it out properly.

For each medical student, the total score for the OSCE (maximum 13 points, minimum 0 points) marked by the member of staff was compared with that obtained by the dental student.

A total of 147 medical students sat the exam, although the results were not made available to us for 22 of the medical students. Thus the results for 125 medical students were analysed.

Since there were three pairings of staff plus dental student (ie one OSCE held simultaneously in three venues), comparisons were made initially for each pairing separately. When all three dental students were combined and compared with all three members of staff, mean values of 0.92 and 0.93 respectively, were obtained. Thus a very close agreement was identified, between student and staff members, in terms of the overall result for the OSCE questions on oral examination.

Using Mann-Whitney tests, the hypothesis that the medium score of marks awarded by the dental student was the

\section{Fig. I Examiners' Checklist}

Please ask the student for an identity label to place on the checklist.

\section{Instructions to Examiners}

The candidates have been given the following instructions.

At this station you will be asked to examine the oral cavity.

Please repeat exact instruction to candidate.

Please indicate your mark by using [-] in the appropriate column.

\section{Marking Schedule}

$0=$ Not Done, $1 / 2=$ Done but Incorrectly, I = Done Satisfactorily

Introduction

Explanation

Wearing gloves

Inspection of face asymmetry/colour

Position behind patient

Palpation of lymph glands submental, submandibular, sublingual

Inspection of palpation of:

Lips

- Tongue

- Buccal mucosa

- Hard palate

Use of gauze swabs

Use of lighting

Use of spatula

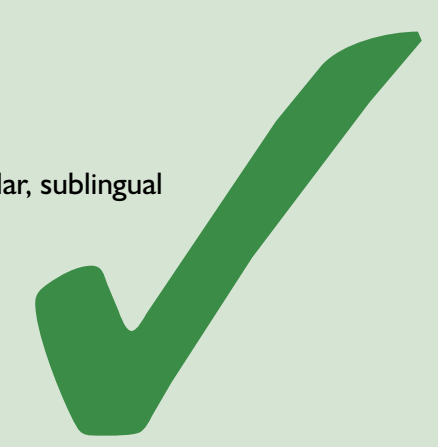

Max 13 marks

same as the median score of marks awarded by the member of staff was not rejected in each of the three pairings A, B, C. Non-parametric $95 \%$ confidence intervals for the difference in scores in the three pairings were: A: $(-0.5,0)$; B: $(-0.5,0.5)$; C: $(-0.5,0)$. The overall agreement can be seen in Table 1, which lists the frequency in which each pairing gave the same score for the OSCE, one mark difference, two marks difference and so on. When we allowed for a difference of one mark (eg a total score of 12 by dental student, 13 by member of staff), the percentage agreements for pairings A, B and C were 95\%, $100 \%$ and $80 \%$ respectively. When all were combined, an overall level of agreement (allowing for a maximum difference of one mark) was $93 \%$. A high level of consistency was thus achieved. Indeed, a difference of more than one mark only occurred for nine medical students examined (out of the total available, $n=125$ ). Even then the maximum difference recorded was three marks.
There were no cases in which the total mark allocated by the dental student compared with that from the member of staff, differed by more than three marks.

\section{Discussion}

The level of correlation between the dental student examiners and the senior examiners was high. However, certain anomalies were apparent. Overall, pairing A had the closest agreement on the majority of items on the checklist. However, on certain items pairing $\mathrm{C}$ were better correlated yet overall had less agreement. These findings need to be discussed in the context of current knowledge of the role of the examiner in the assessment process.

Classical test theory and Generalisability theory assumes that behaviour does not change over time. However, in the assessment process the performance of the examinees as well as the examiners changes. ${ }^{19}$ Examiners with experience often judge performance in the light of their own experience. ${ }^{7}$ There may be concern that the final 


\section{EDUCATION student examiners}

\begin{tabular}{|c|c|c|c|c|c|}
\hline Table I & \multicolumn{5}{|c|}{$\begin{array}{l}\text { Comparison of levels of agreement between dental student and } \\
\text { staff examiners for each pairing ( } A, B, C \text {. See text for details } \\
\text { (O = complete agreement, I = difference of one mark between } \\
\text { examiners, etc.) }\end{array}$} \\
\hline \multicolumn{2}{|c|}{$\begin{array}{l}\text { Absolute difference in total } \\
\text { score as determined by dental } \\
\text { student and compared with } \\
\text { staff examiner }\end{array}$} & $A$ & B & $C$ & All \\
\hline \multicolumn{2}{|c|}{0.0} & 20 & 23 & 12 & 55 \\
\hline \multicolumn{2}{|c|}{0.5} & 15 & 17 & 9 & 41 \\
\hline \multicolumn{2}{|c|}{1.0} & 8 & 5 & 7 & 20 \\
\hline \multicolumn{2}{|c|}{1.5} & 0 & - & 5 & 5 \\
\hline \multicolumn{2}{|c|}{2.0} & I & - & I & 2 \\
\hline \multicolumn{2}{|c|}{2.5} & I & - & - & I \\
\hline \multicolumn{2}{|c|}{3.0} & 0 & - & I & I \\
\hline & & 45 & 45 & 35 & 125 \\
\hline
\end{tabular}

year dental students, while able to assess individual components of the task, may have been unable to identify concerns in the overall quality of performance.

In maximising the reliability of the examination, random errors were controlled by minimising the fluctuations in the external environment and by the discussion of the checklist by the examiners prior to the exam, in other words having a shared view of the behaviour paradigm being assessed. However, concern has previously been expressed that expert examiners are often constrained by checklists. Norman has indicated that breaking down the task into discrete parts using a checklist does not necessarily make the assessment more reliable than a global rating. ${ }^{19}$ This may have influenced the results in this pilot. Refinements to the checklist and the use of a global rating scale may help to increase the reliability of this station.

Freidman and Menin have also suggested that expert examiners are able to differentiate the effects of systematic error from those of random error and their effect on performance outcome. ${ }^{7}$ This would imply that there should be less correlation between the dental students and their expert co-examiners. However, we would suggest that from our results in the assessment of a procedural skill, that may be used in a wide variety of clinical contexts, the need for expert examiners is not necessary.

To some extent our conclusions are only valid for the three randomly selected dental students. It could have arisen by chance that the three most reliable dental students had been chosen (although as previously described, those students had not been specifically selected to teach the medical students). However, given the constraints of the examination and space available, it was not possible to have more than two examiners for this station.

There may be concern at the use of students to mark fellow undergraduates. However, the dental students were all about to qualify and therefore were fully aware of their professional role. Furthermore, the results indicate no significant difference between the staff and student examiner. There was also a member of staff present as an examiner. Even if the dental student was the sole examiner, inappropriate communication would be unlikely given that: a) A site supervisor regularly patrolled the station, and b) The simulated patients were trained lay people. The station could also be videoed.

One of the future considerations for this station is to video the assessment process and ask an expert and a novice medical marker to mark the student performance and then to compare this with the examiners present at the station.

We do not know what measure of agreement may have been obtained if comparing scores from two members of staff. This will be undertaken in a future study. Rater bias is considered not a problem if all students are scored by the same rater and a relative standard issued. ${ }^{20}$ This was not possible in our study, as the examination took place in three different venues at the same time.

'Hawks' and 'doves' always exist in any assessment process. ${ }^{20}$ The briefing meeting and the discussion of the checklist prior to the examination should have minimised this well recognised cause of inter rater reliability. On some occasions, however, the students appeared to be more hawkish. This may have been due to a systematic error affecting realiability caused by dental student bias. They had been involved in the teaching programme and therefore had previous exposure to the medical students and perhaps had higher expectations of performance.

One aspect to emerge from the study is the identification of tasks within the OSCE that should be considered for deletion or modification. In this area there has not been close agreement between dental student and staff member, perhaps suggesting that there is difficulty in interpreting what the medical student does successfully, eg as in response to inspection of facial asymmetry or inspection of the lips.

The process of this study has enabled us to reflect and focus on what the required outcome is in relation to this station and the programme on gastroenterology and oral health that is offered in the undergraduate medical curriculum. ${ }^{21}$ In relation to this it is also important to question the appropriate representation of the station in relation to its generalisability to real practice. To that end, feedback was obtained for both the medical and dental students (paper in preparation). 


\section{Conclusion}

This pilot study illustrates that peer groups that have been used to teach other health professionals can be used successfully as examiners in an OSCE assessment. Although it may be said to be only true for these three randomly selected dental students, it does nevertheless, provide further evidence supportive of interprofessional education. An area which in the future may lead to better collaboration between different health professionals, to the benefit of their patients. ${ }^{22}$ They also gain insight into evaluating their own level of understanding. ${ }^{5}$ This practical peer collaboration within the joint Faculty of Medicine, Dentistry \& Nursing in the assessment process can only lead to a better understanding of professional roles in the delivery of healthcare.

1 Education Group for Guidelines on Education Guidelines for evaluating papers on educational interventions. $\mathrm{Br}$ Med J 1999; 318: 1265-1267.

2 Davenport E S, Davis J E C, Cushing A M, Holsgrove G J. An innovation in the assessment of future dentists. Br Dent J 1998; 184: 192-195.

3 Newble D I, Entwhistle N H. Learning styles and approaches: Implications for medical education. Med Educ 1986; 20: 162-175.

4 Harden R M, Gleeson F A. Assessment of clinical competence using an objective structured clinical examination (OSCE). Med Educ 1979: 13: 41-54.

5 Heylings D J, Stefani L A J. Peer assessment feedback marking in a large medical anatomy class. Med Educ 1997; 31: 281-286.

6 Sobral D T. Productive small groups in medical studies: training for cooperative learning. Med Teacher 1998; 20: 118-121.

7 Friedman M, Mennin S P. Rethinking Critical Issues in Performance Assessment. Acad Med 1991; 66: 390-395.

8 Hamilton J. Training for skills. Med Educ 1995; 29: 83-87.

9 Multidisciplinary education. Editorial. Med Educ 1995; 29: 329-331.

10 Horder J. Interprofessional co-operation: the vision and the challenge. Conference Reports. J Int Prof Care 1992; 6: 73-75.

11 Bowden J, Scully C. Dentistry and total oral health. Br Med J 1989; 298: 186.

12 Strategic Plan 1992-1997. Health Education Board for Scotland, 1993. Edinburgh, published by HEBS.

13 Macfarlane G J, Boyle P, Scully C. Rising mortality from cancer of the tongue in young Scottish males. Lancet 1987; Vol 2: 912.

14 O’Brien M. Office Population Census \&
Surveys. Children's Dental Health in the UK. London: HMSO, 1994.

15 Scully C, Malamos D, Levers B G H, Porter S R Prime S S. Sources and patterns of referrals of oral cancer; role of general practitioners. $\mathrm{Br}$ Med J 1986; 293: 599-601.

16 Guggenheimer J, Verbin R S, Johnson J T, Horkowitz C A, Myers E N. Factors delaying the diagnosis of oral and oropharyngeal carcinomas. Cancer 1989; 64: 932-935.

17 General Medical Council. Tomorrow's Doctors. Recommendations on Undergraduate Medical Education. London: General Medical Council, 1993.

18 Harden R M, Davis M H, Crosby J R. The new Dundee medical curriculum : a whole that is greater than the sum of the parts. Med Educ 1997; 31: 264-271.

19 Norman G R. Reliability and Construct Validity of some Cognitive Measures of Clinical Teaching. Teach Learn Med 1989; 1: 194-199.

20 Newble D, Dawson B, Dauphinee D, Page G, Macdonald M, Mulholland H, Swanson D, Thomson A, van der Vleuten C. Guidelines for Assessing Clinical Competence. Teaching \& Learning Med 1994; 6: 213-220.

21 Ogden G R, Ker J. Re: Kissun et al. General medical practitioners' knowledge of the specialty of oral and maxillofacial surgery (letter). Br J Oral \& Maxillofac Surg 1998; 36 : 479-480.

22 Horder J. Interprofessional Education. Med Educ 1992(b); 26: 427-528. 